\title{
Avaliação do Conhecimento da Ética Médica dos Graduandos de Medicina
}

\author{
An Assessment of Medical Students' \\ Knowledge of Medical Ethics
}

\author{
Moacir Fernandes de Godoy \\ Hanna Rafaela Alves Ferreira ${ }^{I}$ \\ Otávio Augusto Ferreira Dalla Pria
}

PALAVRAS-CHAVE

- Ética Médica;

- Educação de Graduação em Medicina;

- Aprendizagem;

- Educação Médica;

- Ensino;

- Conhecimento.

\section{KEYWORDS}

- Medical Ethics;

- Medical School;

- Learning;

- Medical Education;

- Teaching;

- Knowledge.
Recebido em: 03/11/2012

Reencaminhado em: 26/06/2013

Aprovado em: 07/04/2014

\section{RESUMO}

Introdução: Várias escolas de Medicina do País criaram disciplinas para o ensino de Ética Médica, mas o impacto dessa intervenção não tem sido claramente questionado. Objetivo: Mensurar o conhecimento referente ao tema Ética Médica adquirido pelos alunos do curso de Medicina da Faculdade de Medicina de São José do Rio Preto (Famerp). Métodos: Trata-se de estudo transversal descritivo. Os graduandos do ano letivo de 2012 responderam a um questionário autoaplicável com 12 questões objetivas, com três opções (verdadeiro, falso, desconhece), elaboradas com base no Código de Ética Médica (CEM). Os dados foram analisados com auxílio da estatística descritiva e inferencial; consideraram-se significantes valores de $p \leq 0,05$. Resultados: Dos 387 alunos, 251 responderam ao questionário (64,9\%). Houve nítida evolução de conhecimento da primeira para a quarta série, porém, a partir da quarta série, houve estagnação do conhecimento. Além da estagnação observada, houve baixa taxa de acertos na sexta série (56,2\%), apesar de ter sido a mais alta. Conclusão: Há necessidade do ensino formal da Ética Médica durante todos os anos da graduação, já que o modelo atual, com ensino apenas na terceira série, se mostrou ineficaz.

\section{ABSTRACT}

Introduction: Several of Brazil's medical schools have established course modules for teaching medical ethics, but the impact of this intervention has yet to be specifically addressed. Objective: To measure knowledge on the topic of Medical Ethics acquired by students at the São José do Rio Preto Faculty of Medicine (Famerp). Methods: In this cross-sectional study, the graduate class of 2012 answered a questionnaire with twelve self-applicable objective questions with three alternatives (true, false, don't know) based on the Code of Medical Ethics. Data was analyzed using descriptive and inferential statistics and considered significant if $P \leq 0.05$. Results: Of the 387 students, 251 completed the questionnaire (64.9\%). A clear evolution of knowledge was revealed from the first to fourth grade but from the fourth grade onwards, there was stagnation of knowledge. Besides the stagnation observed, there was a low-hit ratio in the sixth grade (56.2\%), despite it being the highest grade. Conclusion: There is a need for the formal teaching of medical ethics during all of the years of the degree course, since the current model, taught only in the third grade, has proven itself to be ineffective. 


\section{INTRODUÇÃO}

A incorporação de conceitos éticos às normas profissionais é fundamental para edificar de forma justa e humanística a Medicina ${ }^{1}$. Não só as leis, mas as determinações próprias de órgãos reguladores da área da saúde, como o Conselho Nacional de Saúde (CNS), e dos conselhos profissionais, têm papel fundamental na regulamentação bioética, que utiliza quatro princípios básicos — autonomia, beneficência, não maleficência e justiça - que fazem parte do cerne do código de conduta da profissão médica e dos de outras profissões da saúde ${ }^{2-5}$.

As leis garantem o direito à saúde, enquanto o governo garante as políticas públicas para a sua promoção ${ }^{6}$. Nesse contexto, os profissionais das ciências da saúde, dentre eles os médicos, interferem diretamente na garantia desse bem. Assim, é necessária uma regulação pautada na ética, que, nesse caso, é realizada por resoluções do Conselho Federal de Medicina, determinadas com base no Código de Ética Médica $(\mathrm{CEM})^{2}$.

O Brasil teve seu primeiro Código de Ética Médica em 1867 , sendo criados mais sete até $1988^{1}$. Sob essa perspectiva de aprimoramento da normatização do exercício da medicina, o Conselho Federal de Medicina criou, a partir de uma atualização do Código de 1988, a nova edição do CEM², lançada em 2009, que tem por base as decisões da IV Conferência Nacional de Ética Médica². O objetivo da alteração do Código foi, portanto, se atualizar quanto à subordinação das normas deontológicas à Constituição Federal e Leis que abordam o exercício da prática médica, bem como o ensino desta e a administração dos serviços de saúde.

A transgressão do Código, especificamente das normas deontológicas, pode levar o infrator a receber penas legais ${ }^{2}$. Logo, nota-se a fundamental importância do conhecimento, por parte dos profissionais e estudantes, das normas que regem a profissão e dos conceitos éticos que convergiram para a criação de tais normas.

Para que as novas gerações de médicos possuam esse conhecimento, é sugestão de Grisard ${ }^{7}$ e resolução da World Medical Association ${ }^{8}$ que haja uma disciplina específica para o tema no currículo da graduação médica, a fim de apresentar ao estudante os principais conceitos e princípios éticos que regerão sua prática.

Infelizmente, há vários anos se tem notado um aumento no número de processos e punições a médicos que cometeram infrações que ferem o referido Código ${ }^{9}$. Isto pode demonstrar desconhecimento sobre o tema e nos leva a crer na necessidade de medidas eficazes para promover o processo de ensino-aprendizagem da Ética Médica desde a graduação, buscando identificar e corrigir falhas, para que o conhecimento adquirido pelos estudantes sobre o assunto não seja incorreto, insuficiente ou efêmero.

Trazendo tais premissas para a realidade da Faculdade de Medicina de São José do Rio Preto (Famerp), notou-se a urgente necessidade de avaliar em que aspectos o conhecimento de preceitos de Ética Médica difere entre estudantes agrupados segundo as séries do curso de Medicina na Famerp. Considerando-se a amplitude da temática ${ }^{10,11}$, para melhor avaliação e restrição do conteúdo avaliado, tomou-se por base ideal mensurar apenas o conhecimento sobre o CEM lançado em 2009. Foi objetivo do trabalho apontar as deficiências e sugerir formas de resolvê-las, de modo que possam servir como base para demais instituições de ensino.

\section{MATERIAIS E MÉTODOS}

\section{População e Amostra}

Trata-se de um estudo transversal descritivo que avaliou a população de 387 discentes, número de matriculados no curso de Medicina da Famerp. Esperava-se uma amostra mínima de $50 \%$ dos alunos, e atingiu-se um total de $64,8 \%$. Não foram incluídos na avaliação os dois acadêmicos elaboradores do projeto. Este projeto foi aprovado pelo Comitê de Ética em Pesquisa da Famerp.

\section{Coleta de Dados}

Os graduandos da primeira à sexta série médica do ano letivo de 2012 tiveram acesso ao questionário, que permitia a identificação do avaliado apenas por série e não por identidade. Tal acesso ocorreu de fevereiro a agosto de 2012, sendo aplicado um impresso para cada aluno nas salas de aula. Não houve tempo limite para sua devolução aos autores, de modo que os acadêmicos se comprometeram apenas a não buscar nenhuma fonte de consulta.

\section{Descrição do Questionário}

Trata-se de um questionário autoaplicável, com 12 questões objetivas elaboradas com base no conteúdo do CEM publicado pelo Conselho Federal de Medicina em 2009. Na elaboração das questões, foram consultados trabalhos relacionados ao tema, buscando-se um modelo se possível padronizado, que pudesse avaliar satisfatoriamente o conhecimento da Ética Médica na graduação, de modo a permitir comparações das alterações do conhecimento no decorrer do curso ${ }^{10,12}$. Nenhum deles, no entanto, satisfez as expectativas dos autores quanto ao modelo de questões, devido, principalmente, ao fato de não permitirem a manifestação do desconhecimento sobre o assunto avaliado, induzindo o aluno a responder a todas as 
questões, mesmo que não tivesse conhecimento sobre alguma. Dessa forma, foi criado um questionário próprio a partir do conteúdo do CEM. As questões foram elaboradas por meio da transcrição dos trechos, com mínimas modificações para torná-los questões objetivas. Os alunos puderam responder objetivamente uma dentre três opções: a afirmação é verdadeira, a afirmação é falsa ou desconhecimento sobre o assunto. A coleta de dados foi realizada pelos acadêmicos elaboradores do projeto.

\section{Análise de dados}

Os dados coletados foram planilhados em Excel 2007 e analisados com o auxílio da estatística descritiva e inferencial, empregando-se para isso o programa de análise estatística StatsDirect - Versão 1,9,15 (30/11/2011). A análise das variáveis categóricas foi realizada aplicando-se o teste exato de Fisher. Foram considerados significantes valores de $\mathrm{p}$ inferiores ou iguais a 0,05. Para complementação da análise das médias foi utilizado o teste de tendência linear.

\section{RESULTADOS}

Dentre os 387 alunos matriculados no curso de Medicina da Famerp no ano letivo de 2012, 64,9\% responderam ao questionário. A distribuição da abrangência por sala foi: primeira série 42/ 67 (62,7\%); segunda série 41/63 (65,1\%); terceira série $43 / 65$ (66,2\%); quarta série 41/63 (65,1\%); quinta série 42/66 $(63,6 \%)$ e sexta série $42 / 63(66,7 \%)$.

O conhecimento da Ética Médica através das séries está demonstrado nos Gráficos 1 e 2.

\section{GRÁFICO 1}

Acertos, Erros e Desconhecimento por Série Avaliada

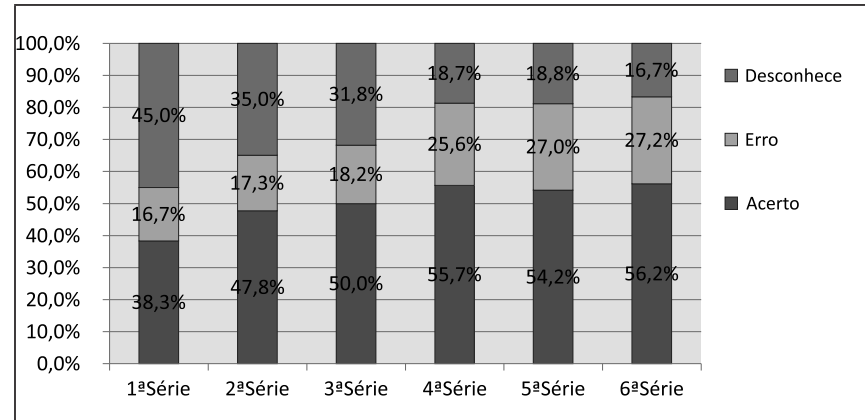

Considerando os acertos por série, entre a primeira e a segunda observa-se um aumento significativo do número de acertos $(p=0,0026)$. Entre a segunda e terceira séries, terceira e quarta, quarta e quinta, quinta e sexta séries, não houve significância estatística entre a diferença de acertos. Entretanto, houve aumento progressivo na média de acertos entre a primeira e a sexta série, a qual atingiu $55,8 \%$ da pontuação máxima e elevação correspondente a 17,5\% em relação à primeira série. Ao considerarmos o teste para tendência linear, foi evidenciada tendência crescente significativa ( $p<0,001)$ na média de acertos da primeira à sexta série, com magnitude do efeito, ou seja, a progressão na vivência do curso, discreta (r2 $=0,092$ ).

Na análise dos erros por série, entre a primeira e segunda séries, e segunda e terceira séries, não houve diferença estatística. Entretanto, entre a terceira e quarta séries, a comparação entre os erros alcançou significância estatística ( $p=0,0048)$, demonstrando aumento dos erros na quarta série. Entre a quarta e quinta séries, quinta e sexta, não houve significância estatística na variação de erros.

GrÁfICO 2

Evolução do conhecimento entre as séries

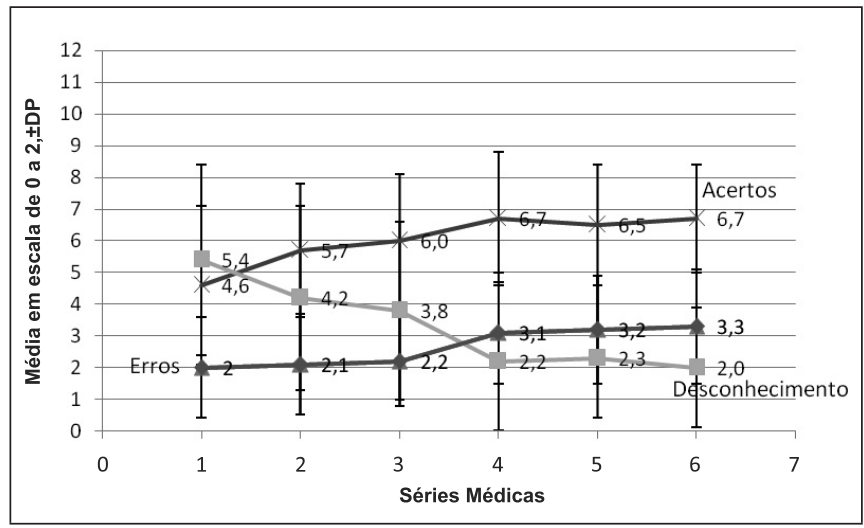

Entre a primeira e a segunda série, houve significante diminuição do número de questões que os estudantes referiram desconhecer $(p=0,0012)$. Entre a segunda e a terceira série, não foi encontrada significância estatística. Entre a terceira e quarta série, houve diferença significativa ( $\mathrm{p}=$ 0,0048), estando esta com menor índice de desconhecimento. Entre a quarta e quinta, quinta e sexta séries, não houve diferença significativa entre o número de desconhecimento de questões.

Nota-se ainda que houve desigualdade na variação dos acertos, erros e desconhecimentos e, inclusive em determinados temas, a sexta série teve desempenho igual ou inferior ao da primeira série, como observado nos quesitos $6^{\circ}, 8^{\circ}$ e $12^{\circ}$ (Tabela 1). 
TABELA 1

Respostas corretas e desconhecimentos por série do curso de Medicina da Famerp

\begin{tabular}{|c|c|c|c|c|c|c|}
\hline \multirow[b]{2}{*}{ Questão } & \multicolumn{6}{|c|}{ Acerto (A) / Desconhecimento (D) } \\
\hline & $\begin{array}{c}1^{\text {a }} \text { série } \\
\text { A/D }\end{array}$ & $\begin{array}{c}2^{a} \text { série } \\
\text { A/D }\end{array}$ & $\begin{array}{c}3^{a} \text { série } \\
\text { A/D }\end{array}$ & $\begin{array}{c}4^{\mathrm{a}} \text { série } \\
\mathrm{A} / \mathrm{D}\end{array}$ & $\begin{array}{c}5^{\text {a }} \text { série } \\
\text { A/D }\end{array}$ & $\begin{array}{c}\text { 6-a }^{\text {série }} \\
\text { A/D }\end{array}$ \\
\hline
\end{tabular}

O Código de Ética Médica, elaborado pelo Conselho Federal de Medicina, tem respaldo legal, e a transgressão das normas deontológicas sujeitará os infratores às penas disciplinares previstas em lei. (verdadeiro)

Os hospitais públicos sempre têm o direito de limitar as escolhas, por parte dos médicos, de meios para estabelecimento do diagnóstico. (falso)

É dever do médico esclarecer o trabalhador sobre as condições de trabalho que ponham em risco sua saúde, devendo comunicar o fato aos empregadores responsáveis. (verdadeiro)

O médico pode sofrer punição disciplinar legal caso emita receitas ou laudos ilegíveis. (verdadeiro)

O médico deve ajustar previamente com o paciente o custo estimado dos procedimentos. (verdadeiro)

É vedado ao médico fazer referência a casos clínicos identificáveis, exibir pacientes ou seus retratos na divulgação de assuntos médicos, em meios de comunicação em geral, mesmo com autorização do paciente. (verdadeiro)

O médico que preste depoimento como testemunha pode revelar sigilo profissional para colaborar com as investigações. (falso)

O médico sempre estará impedido de revelar fato de que tenha conhecimento em virtude do exercício de sua profissão, mesmo que seja para expor o paciente a processo penal. (falso)

É vedado ao médico manter vínculo de qualquer natureza com pesquisas médicas envolvendo seres humanos que usem placebo em seus experimentos quando houver tratamento eficaz e efetivo para a doença pesquisada. (verdadeiro)

É vedado ao médico participar de anúncios de empresas comerciais, qualquer que seja sua natureza, valendo-se de sua profissão. (vedadeiro)

O médico portador de doença incapacitante para o exercício profissional, apurada pelo Conselho Regional de Medicina, em procedimento administrativo, com perícia médica, terá seu registro suspenso enquanto perdurar sua incapacidade. (verdadeiro)

A medicina não pode, em nenhuma circunstância ou forma, ser exercida como comércio. (verdadeiro)

$$
61,9 \% / 33,3 \%
$$

$65,9 \% / 31,7 \%$

$69,8 \% / 25,6 \%$

$80,5 \% / 4,9 \%$

$54,8 \%$ / 16,7\%

$85,7 \% / 14,3 \%$

$37,5 \% / 52,4 \%$

$61,0 \% / 36,6 \%$

$65,1 \% / 30,2 \%$

$73,2 \%$ / $22,0 \%$

$66,7 \%$ / 21,4\%

$76,2 \% / 14,3 \%$

$61,9 \% / 31,0 \%$

$73,2 \% / 22,0 \%$

$58,1 \% / 27,9 \%$

$70,7 \%$ / $14,6 \%$

$71,4 \% / 4,8 \%$

$71,4 \% / 7,1 \%$

$78,0 \%$ / $17,1 \%$

$83,7 \%$ / $11,6 \%$

$82,9 \% / 7,3 \%$

$88,1 \% / 7,1 \%$

$92,9 \% / 4,8 \%$

$42,9 \% / 54,8 \%$

$53,7 \% / 39,0 \%$

$60,5 \% / 34,9 \%$

$73,2 \% / 19,5 \%$

$73,8 \%$ / $14,3 \%$

$64,3 \%$ / $26,2 \%$

$33,3 \% / 28,6 \%$

$43,9 \% / 31,7 \%$

$37,2 \% / 30,2 \%$

$19,5 \% / 4,9 \%$

$35,7 \%$ / $11,9 \%$

$33,3 \% / 7,1 \%$

$19,0 \% / 47,6 \%$

$34,1 \% / 29,3 \%$

$20,9 \% / 34,9 \%$

$43,9 \% / 26,8 \%$

$52,4 \%$ / $28,6 \%$

$54,8 \% / 9,5 \%$

$31,0 \% / 54,8 \%$

$34,1 \% / 41,5 \%$

$44,2 \% / 34,9 \%$

$46,3 \%$ / $24,4 \%$

$38,1 \%$ / $26,2 \%$

$40,5 \% / 16,7 \%$

$11,9 \% / 50,0 \%$

$12,2 \% / 41,5 \%$

$32,6 \%$ / $20,9 \%$

$46,3 \% / 9,8 \%$

$42,9 \% / 19,0 \%$

$47,6 \% / 11,9 \%$

$21,4 \%$ / $54,8 \%$

$29,3 \% / 46,3 \%$

$46,5 \% / 34,9 \%$

$46,3 \% / 24,4 \%$

$45,2 \% / 21,4 \%$

$54,8 \% / 16,7 \%$

Média acertos/Média desconhecimento

$45,2 \% / 33,3 \%$

$63,4 \% / 24,4 \%$

$65,1 \% / 23,3 \%$

$61,0 \% / 17,1 \%$

$59,5 \% / 16,7 \%$

$42,9 \% / 11,9 \%$

$4,6 \pm 2,5 / 5,4 \pm 3 \quad 5,7 \pm 2,1 / 4,2 \pm 2,9 \quad 6,0 \pm 2,1 / 3,8 \pm 2,8 \quad 6,7 \pm 2,1 / 2,2 \pm 2,6 \quad 6,5 \pm 1,9 / 2,3 \pm 1,9 \quad 6,7 \pm 1,7 / 2,0 \pm 1,9$ 


\section{DISCUSSÃO}

Sabemos que o conteúdo dos temas Bioética e Ética Médica são amplos, e seria uma enorme dificuldade avaliar apropriadamente tal conhecimento na graduação ${ }^{10}$, sobretudo pelas recomendações de que o ensino da disciplina tenha por objetivo capacitar os médicos para resolver problemas éticos em geral $^{11}$. Porém, considerando que um estudante de Medicina deve se formar com, no mínimo, o conhecimento ético presente no CEM, propôs-se elaborar uma forma de avaliação objetiva, que pudesse, de forma inédita, quantificar o ganho de informações básicas sobre Ética Médica, ao menos no que diz respeito à deontologia.

O objetivo principal deste trabalho, portanto, foi mensurar a evolução do conhecimento sobre o tema Ética Médica, baseando-se no CEM-2009, entre graduandos de Medicina de uma faculdade pública, cujo método de ensino é o tradicional e, como sugerido pelo estudo da World Medical Association ${ }^{8}$ e por Grisard ${ }^{7}$, possui uma disciplina que aborda especificamente o assunto na graduação.

À semelhança de mais da metade das instituições de ensino médico que ministram tais disciplinas na terceira ou quarta série $^{7}$, na Famerp ela é oferecida no último trimestre da terceira série. Assim, durante a disponibilização dos questionários aos participantes, as três primeiras séries avaliadas não haviam tido contato "disciplinar" com o tema, ao contrário das três últimas séries - inclusive, a atual sexta série foi a primeira turma de formandos cuja disciplina que aborda o tema Ética Médica se baseou no novo Código, que já havia sido aprovado quando esta foi ministrada.

Levou-se em consideração que, além da disciplina, que sob sua ementa aborda o tema, o conhecimento da Ética Médica fosse discutido e, assim, construído, numa abordagem multidisciplinar ao longo do curso, por meio do contato docente-discente, tanto por experiência profissional transmitida pelo docente preceptor, quanto por discussão de casos na prática da graduação - abordagem esta de certa forma diluída durante o curso, como Grisard ${ }^{7}$ observou em outras instituições.

Com base no modelo de ensino da Ética adotado pela Famerp, buscou-se por publicações que abordassem o tema de forma semelhante, conforme a proposta para este trabalho. Porém, os artigos encontrados ${ }^{10,12}$ não condiziam com o modelo de avaliação idealizado. O modelo de questionário adotado neste trabalho permitiu avaliar o que o discente considera saber (e erra ou acerta) versus o que ele admite não ter conhecimento, permitindo, assim, maior leque de interpretações. Outro aspecto que dificultou comparar nosso projeto com outros já realizados foi o fato de que o presente CEM foi lançado re- centemente $^{2}$, o que restringiu correlações de semelhança pela escassez de trabalhos realizados adotando tal fonte.

Com uma base comparativa de escassos outros estudos ${ }^{7,10}$, esperávamos que os discentes se formassem com conhecimentos mínimos efetivos sobre o CEM, devido à relevância de um código de conduta para uma profissão. A expectativa inicial dos elaboradores do projeto era encontrar uma curva de aprendizado crescente nas séries subsequentes, com maior diferença entre as séries que já tivessem cursado a disciplina que trata de temas éticos especificamente, chegando-se a um ápice na sexta série médica - idealmente próximo de 100\% de acertos - , demonstrando que o modelo de ensino da Ética Médica na Famerp seria adequado.

Ao compararmos séries imediatamente subsequentes, pudemos notar que apenas entre a primeira e segunda série, e entre a terceira e a quarta série houve diferença estatisticamente significante, apesar de diferenças isoladas terem sido encontradas entre todas as séries (Gráfico 1).

Entre a primeira e a segunda série, houve diminuição do desconhecimento, acompanhada por um aumento relevante de acerto e manutenção estatística de erros (Gráfico 2), sugerindo que o conhecimento que os alunos adquiriram sobre o tema complementou de forma correta e concreta todo o conhecimento prévio. Entre a terceira e a quarta série, houve a maior redução do desconhecimento sobre os assuntos abordados. Esta, porém, foi acompanhada de um aumento relevante dos erros, sugerindo que o conteúdo do curso específico administrado no fim da terceira série e demais conhecimentos adquiridos neste período, na verdade, não ficaram bem sedimentados. Assim, o fato de os alunos terem tido contato com mais temas através da disciplina específica causou a queda na taxa de desconhecimentos, porém, por ainda não estarem preparados o suficiente para acertar os questionamentos do estudo, ocorreu um aumento dos erros mais relevante que o aumento de acertos - isto é, os alunos passaram a conhecer mais assuntos, mas de forma superficial ou incorreta (Gráfico 2).

Inferimos que o aumento estatístico de erros entre a terceira e a quarta série, bem como a permanência de tal proporção de erros após esta série são muito negativos, pois o ideal seria que houvesse redução ou inexistência de erros. Tal redução ou inexistência de erros significaria que, quando o aluno considerasse saber o assunto - e, neste caso, se submetesse a responder se a questão é verdadeira ou falsa - , ele o dominaria corretamente, diferentemente do observado (Gráfico 2).

Tal conceito é muito importante, pois consideramos que é melhor para o discente perceber que não tem domínio sobre determinado assunto do que acreditar que tem, quando, na verdade, não o domina suficientemente. Afinal, aquele que 
tem consciência de que não domina um assunto tem a oportunidade de buscar sabê-lo; já o que considera dominá-lo, mas se enganou, continua a acreditar em seu falso conhecimento, porque ignora este fato.

Foi observada grande semelhança entre o conhecimento da quarta, quinta e sexta sériea, mantendo proporções parecidas de acertos, erros e desconhecimentos. Considerando-se da primeira à sexta série, é possível encontrar uma tendência crescente de ganho de conhecimento. Entretanto, tal ganho só se torna significativo ao compararmos os extremos da amostra ou pelo teste de tendência linear - , demonstrando, portanto, que, apesar de haver crescimento, ele é modesto.

Inferimos, neste ponto, falha na percepção inicial de que o conhecimento ético poderia ser adquirido pela multidisciplinaridade da prática, pela transferência da experiência profissional dos preceptores ou pelas discussões de casos vivenciados na prática, considerando que a metodologia tradicional adotada pela Famerp, apesar de ter focos de prática profissional nas demais séries, tem a maior concentração desta na quarta série médica e no ciclo do internato - quinta e sexta séria médica. Dessa forma, como demonstrado na análise, a curva de aprendizado durante este período prático sofreu pequenas alterações, além de ter atingido uma média que pode ser considerada baixa. Logo, notamos uma preocupante realidade em nossa instituição e que também pode ocorrer em outras instituições cuja metodologia de ensino se assemelha à da Famerp.

Apesar de recomendações sobre a necessidade de uma disciplina específica sobre o tema ${ }^{7,8}$, ficou demonstrado em nosso trabalho que um curso teórico ministrado apenas na terceira série é insuficiente para promover um adequado ganho de conhecimento entre os graduandos de Medicina nem sobre o CEM, nem sobre Ética Médica em seu sentido amplo. E, ainda, que, embora haja a possibilidade de contato e discussões sobre o tema durante o internato, a diluição desse aprendizado também não é benéfica o bastante para edificar o conhecimento. Assim, sugere-se ensinar Ética Médica durante toda a graduação e, conforme Olukoya ${ }^{13}$ propôs, um planejamento específico para maior eficiência, em especial no final da graduação, utilizando-se uma proposta pedagógica real, presente no ementário, e que não fique apenas a cargo de cada preceptor a decisão de discutir ou não temas relacionados à ética com os discentes.

Dessa forma, para que o conhecimento sobre ética fique inerente ao pensamento, o ideal talvez fosse selecionar os principais temas da Ética Médica, compilando-se os que se adaptem melhor a cada estágio e fixando curricularmente no plano de ensino de cada disciplina discussões sobre esses temas na rotina de cada enfermaria, de modo a estimular o gra- duando a analisar suas atitudes com os pacientes, pautando-se especificamente no Código de Ética Médica. Assim, seriam introduzidas na realidade do acadêmico as condutas frente a casos que exijam ações éticas, que com certeza surgirão no cotidiano de sua profissão.

Entretanto, tais alterações curriculares dependem da preparação dos docentes preceptores para discutir tais temas, o que não é realidade na maioria das instituições ${ }^{7,10}$. Portanto, caberia à instituição realizar cursos de capacitação e atualização para aqueles que são preceptores no internato ou práticas profissionais, a fim de que as discussões éticas não fiquem apenas no planejamento ou que os docentes interfiram negativamente no aprendizado dos graduandos, como foi observado em outros estudos ${ }^{14,15,16}$.

Como diversas outras instituições possuem um modelo de ensino da Ética Médica parecido, é possível que esse problema encontrado seja comum. É preciso, portanto, que as demais instituições analisem seus currículos e realizem mais pesquisas com objetivos e métodos semelhantes aos desta, a fim de ampliar comparações com a finalidade de planejar ações efetivas e minimizar as deficiências no ensino da Ética Médica.

Este estudo propõe que a formação médica seja privilegiada com o ensino, curricularmente planejado, da Ética Médica e Bioética especialmente durante o internato e que este ensino se embase numa disciplina específica nos primeiros anos da graduação, a fim de introduzir as informações pertinentes ao tema desde o início da vivência com a medicina, possibilitando o maior número possível de oportunidades para que o estudante se forme com princípios básicos da Ética Médica inerentes em sua forma de pensar.

Ressalta-se como uma das limitações deste trabalho o modo transversal adotado, que impossibilitou comparar a evolução do conhecimento ao longo de seis anos para uma mesma série, o que, associado ao fato de terem sido comparadas amostras não aleatórias de seis turmas potencialmente distintas em mais de um atributo educacional, impede melhor aferição do progresso. Outra limitação importante foi a necessidade de criação de um novo questionário, baseado apenas no CEM, impossibilitando maior abrangência sobre a avaliação do tema.

\section{CONCLUSÃO}

$\mathrm{O}$ estudo mostrou que o conhecimento dos graduandos de Medicina da Famerp sobre o Código de Ética Médica está muito defasado e que o modelo de ensino atual pode ser o principal fator contribuinte para esse problema. Constatou-se a ineficiência especialmente durante o internato, já que não houve 
ganho significativo de conhecimento nesse período, além de uma baixa taxa de acertos. Assim, há necessidade do ensino formal da Ética Médica durante todos os anos da graduação, com ênfase na estruturação de tal ensino no internato, já que o modelo atual, com uma disciplina específica apenas em uma série, mostrou-se ineficaz. Como diversas outras instituições possuem um modelo de ensino semelhante, é necessário realizar mais pesquisas com objetivos e métodos semelhantes aos desta, a fim de ampliar comparações com a finalidade de planejar ações efetivas e minimizar as deficiências no ensino da Ética Médica.

\section{AGRADECIMENTOS}

A Deus, nossos pais, amigos, familiares e também a todos os que colaboraram e responderam aos questionários.

\section{REFERÊNCIAS}

1. Neves NMBC. Códigos de conduta: abordagem histórica da sistematização do pensar ético. Revista Bioética 2008;16(1):109-15.

2. Conselho Federal de Medicina. Código de Ética Médica: resolução CFM n 1931/2009. Brasília: CFM; 2009.

3. Brasil. Ministério da Saúde. Resolução 196/96 do Conselho Nacional de Saúde/MS Sobre Diretrizes e Normas Regulamentadoras de Pesquisa envolvendo seres humanos. Diário Oficial da União; 10 de outubro de 1996.

4. Barbosa AS, Boery RNSO, Boery EM, Filho DLG, Sena ELS, Oliveira AAS. A Resolução 196/96 e o sistema brasileiro de revisão ética de pesquisas envolvendo seres humanos. Rev. bioét (Impr.) 2011;19(2):523-42.

5. Conselho Federal de Enfermagem. Código de Ética dos Profissionais de Enfermagem: Resolução COFEN 311/2007. Rio de Janeiro, 8 de fevereiro de 2007.

6. Brasil. Constituição da República Federativa do Brasil de 1988. Sessão II. Da Saúde; Art. 196 e 197.

7. Grisard N. Ética Médica e Bioética: a disciplina em falta na graduação médica. Bioética 2002; 10(1):97-114.

8. WMA. Resolution on the Inclusion of Medical Ethics and Human Rights in the Curriculum of Medical Schools World-Wide. Adopted by the 51st World Medical Assembly, Tel Aviv, Israel, October 1999.

9. Conselho Regional de Medicina do Estado de São Paulo (CREMESP). Exame do Cremesp agora é obrigatório. [Acessado em 26/09/2012]. Disponível em: http:/ /www. cremesp.org.br/pdfs/exame_cremesp_24_ultimo.pdf.
10. Muñoz D, Muñoz DR. O ensino da ética nas faculdades de medicina do Brasil. Rev Bras Educ Med 2003; 27(2): 114-24.

11. Eckles R, Meslin EM, Gaffney M, Helft PR. Medical ethics education: Where are we? Where should we be going? Acad Med 2005; 80(12):1143-52.

12. Almeida AM, Bitencourt AGV, Neves NMBC, Neves FBCS, Lordelo MR, Lemos KM, Nuñez GR, Barbetta MC, Athanazio RA, Nery-Filho A. Conhecimento e Interesse em Ética Médica e Bioética na Graduação Médica. Rev Bras Educ Med 2008;32(4):437-444.

13. Olukoya AA. Attitudes of medical students to medical ethics in their curriculum. Med Educ 1983; 17(2): 83-6.

14. Satterwhite WM, Satterwhite RC, Enarson CE. Medical students' perceptions of unethical conduct at one medical school. Acad Med 1998;73(5):529-31.

15. Testerman JK, Morton KR, Loo LK, Worthley JS, Lamberton $\mathrm{HH}$. The natural history of cynicism in physicians. Acad Med 1996;71:S43-45.

16. Neitzke G. Teaching medical ethics to medical students: moral, legal, psychological and philosophical aspects. Med Law 1999; 18: 99-105.

\section{CONTRIBUIÇÃO DOS AUTORES}

As seguintes atividades foram desenvolvidas pelos autores:

Hanna Rafaela Alves Ferreira: Concepção, desenho, coleta de dados, análise, interpretação dos resultados e redação final do artigo.

Otávio Augusto Ferreira Dalla Pria: Concepção, desenho, coleta de dados, análise, interpretação dos resultados e redação final do artigo.

Moacir Fernandes de Godoy: Desenho, coleta de dados, análise, interpretação dos resultados e redação final do artigo.

\section{CONFLITO DE INTERESSES}

Declarou não haver.

\section{ENDEREÇO PARA CORRESPONDÊNCIA}

Moacir Fernandes de Godoy

Rua Garabed Karabashian, 570

Bairro Mansur Daud - São José do Rio Preto

CEP 15070-600 - SP

E-mail: mfgodoy@famerp.br 